\title{
Study on Driving Behavior of Public Transport Drivers in Kerala
}

\author{
Sanjai R. J1a \\ ${ }^{1}$ KSCSTE - NATPAC, Thiruvananthapuram, Kerala, India \\ a*sanjairj@gmail.com
}

Keywords: Driver behavior, public transport, crash, violations, errors, lapses

\begin{abstract}
A lot of crashes involving heavy vehicles have been reported over the years in Kerala. Faulty driving behavior is widely regarded as the major cause of such crashes. This study considers the drivers' perceptions and their socio-demographic background to understand the behavioral variations. The study is done based on a questionnaire survey on public transport operators from which their behavioral characteristics are noted. The study area is divided into three parts namely, North, Central and South Kerala with a fixed sample at each of these regions. The sample size is fixed based on Bill Godden's method for infinite population. Accordingly, a sample of 384 vehicles was surveyed from each region. Thus, data for a total of 1,152 public transport vehicles were taken from all three regions namely North, South, and Central Kerala. From this sample, the variations in violations, errors and lapses among drivers are noted based on various causative factors. Analyses of these behavioral factors are done to study the influence on aberrant behavior and accident occurrence in public transport vehicle plying in Kerala. A linear regression model is developed to state the importance of causative factors in the occurrence of crashes.
\end{abstract}

\section{Introduction}

Road accidents are one of the major challenges for the transportation sector of a country. Every day several people die in road accidents and hence road accident is stated as the primary cause of unnatural death in the world. Even though countries take effective measures to reduce the crash problems and to reduce their impacts on the economy, the problem is still a major issue in many developing countries like India.

The study is proposed in the Kerala state of India. Kerala is a state on the south western coast of India with a 38,863 square kilometers geographical area and a 590 kilometer long coastal line. The population of the state is 33.5 million (Census 2011).Roadways act as the major lifeline for the transport needs of the state. Road infrastructure in the state is still in a developing stage with most of the roads are two lanes two way undivided corridors. The existing state of infrastructure along with fast moving vehicles and urbanized lifestyle has increased the safety concerns of the corridors.Of the total accidents in occurring in Kerala, two-wheelers constitute more than half of the total accidents, followed by four-wheelers and heavy vehicles (Economic Review, 2019). Since, heavy vehicles occupies a major portion of the road and gets involved in a large number of accidents despite its lower proportion in vehicle population, it is essential to carry out a study on the safety aspects of heavy vehicles.

According to the Kerala State Economic Review (2019), About 38,485 accidents were registered during 2017 in Kerala, which implies that there are a total of 105 accidents occurring in Kerala per day. Accidents due to Kerala State Road Transport Corporation (KSRTC) buses were 1150, which means that about 3 accidents which involve KSRTC buses occur per day. Accidents due to private stage carrier buses were 2765 , which gives a daily accident number of eight per day. The number of two-wheelers has increased from 58.29 lakh in 2015 to 64.72 lakh in 2016, recording an average annual growth rate of 11.2 percent. Similarly, the daily number of accidents of two-wheelers has increased from 82 in 2015 to 87 in 2016. Two wheeler accidents account for nearly 58 percent of the total accidents reported in the State. Of the 5,629 KSRTC buses, these 1,218 accidents account for about $22 \%$. Comparatively, the private buses which are about $1,71,303$ 
as per registration records are involved in 3,168 accidents $(2 \%)$ in the past year which is lower infraction by about $20 \%$.

Table 1. Total road crashes in Kerala (Source: Economic review, 2019)

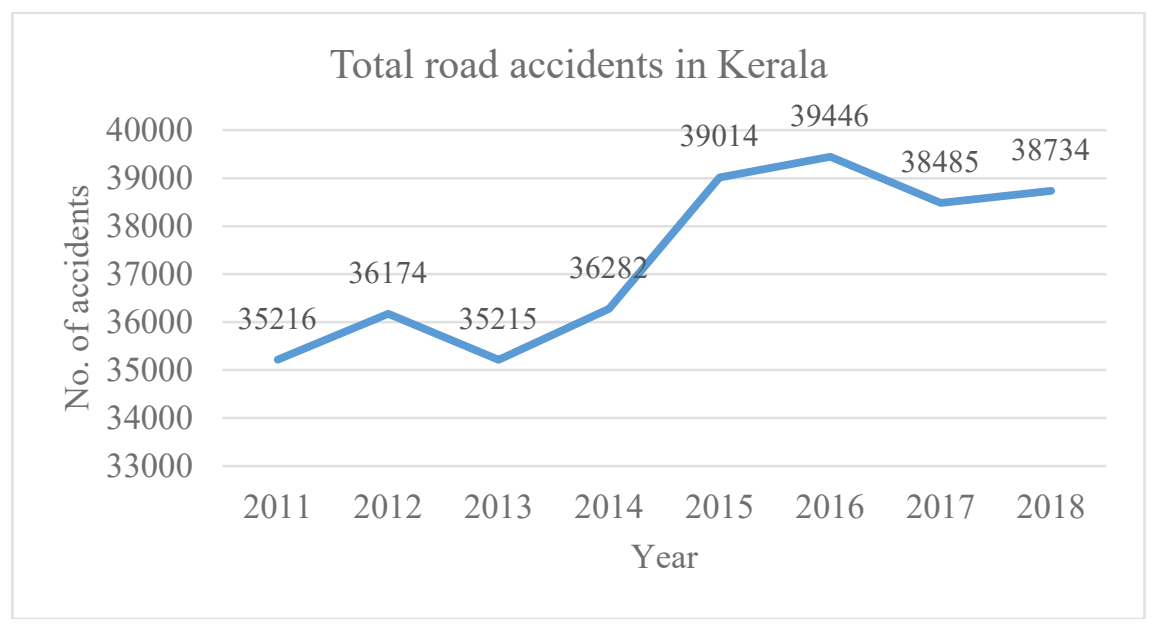

Among the road transport, bus transport is treated as a public provision of services where by one of the prime objectives of this provision has been to meet the social obligation at an affordable, safe and reliable service to the people, both in rural and urban areas. The benefits of bus transport are many and varied: an efficient bus transport system is a major contributor to economic growth, competitiveness and employment. It is highly fuel efficient, economical and requires least road space per passenger kilometer as compared to private modes. It meets the travel needs of commuters in urban and semi-urban areas, for intra and inter-city mobility.

Table 2. Total road crashes involving buses (Source: Economic review, 2019)

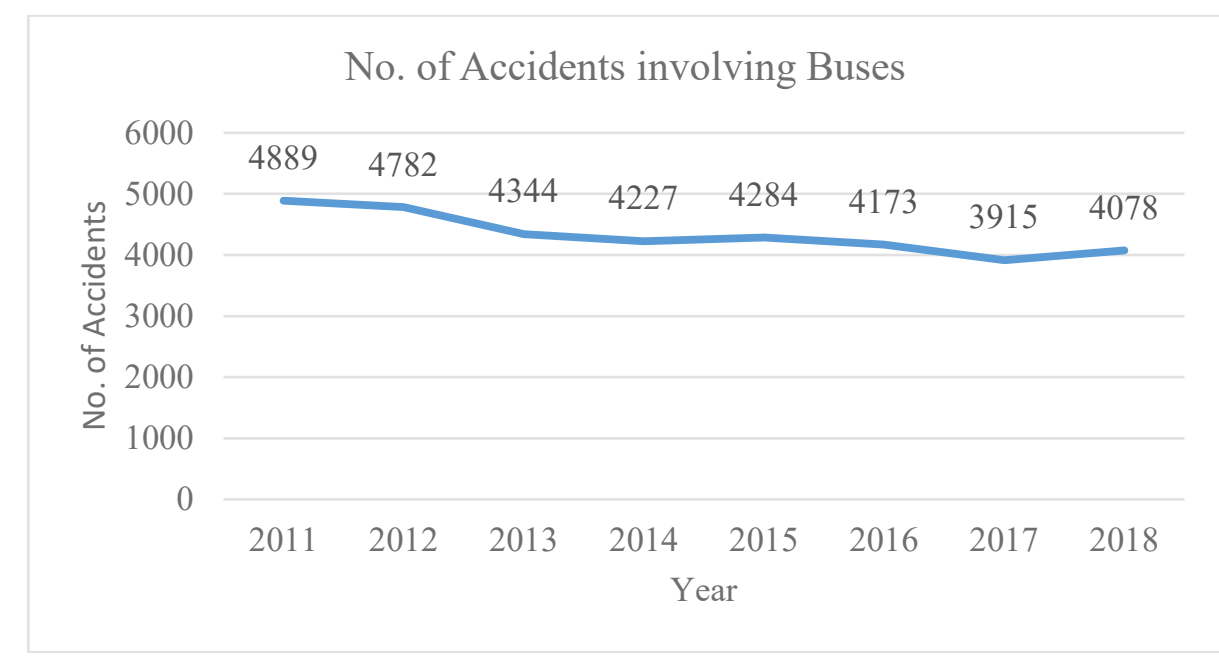

Literatures for this study were obtained through an online bibliographic search by which a number of research publications in the domain of interest were listed. Papers which gave emphasis on modeling of driver behavior were also considered. Driver behavior analysis study has its importance in both transportation engineering as well as in traffic psychology field. There are large number of studies conducted across the world which deals with the study of driver behavior and its impacts on roads. Each study considered certain commonly observed faulty behavior from the parts of the drivers and included these factors as the basis of the questionnaire. From the referred papers, it is identified that a Driver Behavior Questionnaire (DBQ) prepared by Reason et al, 1990 is used for all the studies. Here, the analysis of the behavior of drivers during driving and also their socio demographic characteristics has to be taken into consideration for the purpose of enhancing road safety. 
A 1998 study conducted by MFL Occupational Health Centre reported that tension, mental strain and fatigue are the three main distraction causing factors identified in city bus drivers. Souza et al ,2012, in their study conducted their study to explore the problems of distracted driving for bus drivers, which ultimately came with the conclusion that Passengers related activities are the significant distraction to bus drivers, which ultimately leads to faulty behavior from the part of drivers. The study by Machin et al (2008) focused their works on analyzing the effect of workload and self-reported driver adjustments predicted their health to a good extend. The study revealed that workload acted as a significant predictor of drivers for recovery (fatigue).

Ivancevich et al., (2005) in their study described two different kinds of factors that control character and behavior of an individual. They are primary dimension and secondary dimension. The primary dimension is described as stable factors of a person by the researchers, and it is related to factors such as age, gender and race. Secondary dimension is described as factor which can be considered as variables, such as education, beliefs and experience.

Wishart et.al adopted Manchester Driver Behavior Questionnaire (DBQ) in 1999 to study the self-reported driving behavioural experiences of sample size of Australian fleet drivers. A principal component analysis with varimetrix rotation produces 5 factors that were moderately correlated. Factor analysis was used here for describing variability of the observed, correlated variables. The study revealed that DBQ factors negatively related with aberrant driving behaviors at multivariate level. The study concluded that only the number of kilometers driven each year (e.g., exposure) proved to predict the imposed fines or demerits.

A study by Yonggang Wang et.al conducted their study in the city of Xining, wherein they examined the correlation among various characteristics of professional drivers involved in accidents in China, using a questionnaire survey. Multivariate regression method was made use of to identify the relationship between the risky driving behavior frequency and probability of an accident. According to the study the most frequently reported risky driving behaviors were sleepy, fatigued, or drunk driving' (violation), 'failed to maintain a proper following gap on a slippery road' (error), and 'became impatient with a slow driver: passed a slow driver under risky circumstances' (violation). Other commonly reported risky driving behaviors included: 'forget something unconsciously' (lapse), 'disregard the speed limits' (violation), and 'drive as fast as possibly to pass a yellow light' (violation).

Fikri et.al aimed to study the effect of driver behavior among Indonesian bus drivers on the occurrence of crashes. The study was conducted using Big Five Personality questionnaires along with Driver Behavior questionnaires and Crash Inventory. The study made use of confirmatory factor analysis for analysis part and Structural Equation Model for modeling driver behavior.

The behavioral aspect of the drivers plays a key role in the occurrence of traffic crashes. Heavy vehicles, since they occupy a larger portion of the road should take at most care especially in the areas having restricted road width and other geometric characteristics. The terrain of Kerala is in such a way that there is a lack of adequate width to the road and other roadway features like median, shoulders, etc. Hence, it is essential to study the driver behavior of heavy vehicles thereby analyzing the risk involved in it.

The main objective of this study is to analyze the behavioral pattern and socio-demographic characteristics of public transport vehicle drivers of Kerala and also to compare the driving behavior exhibited on roads by analyzing drivers' knowledge, attitude and notions.

\section{Methodology}

\section{Study Area}

Three regions were selected in Kerala, namely North, Central and South regions. Surveys were conducted in Kozhikode, Kannur and Malappuram districts in north Kerala, Palakkad and Ernakulam districts in central Kerala, Thiruvananthapuram and Kottayam districts in south Kerala. The districts were selected to represent diverse types of operation and geographical areas. 


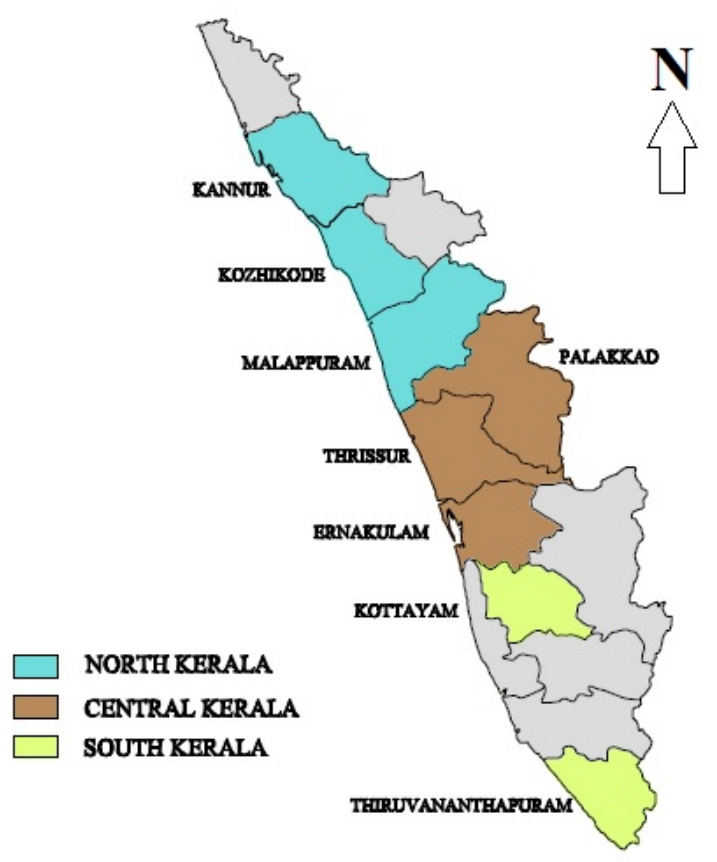

Figure 1. Map of the study area

\section{Sampling Procedure}

The total number of vehicles registered in the respective districts was collected from motor vehicles department. In order to obtain operational characteristics, the sample was fixed based on Bill Godden sample size formula for finite and infinite population, which was found useful in similar works. Thus, the required sample size corresponding to each region was calculated. The sample size for the study was fixed around 384 public transport vehicles in each region based on Bill Godden's sample size formula with $90 \%$ confidence level. Thus, data for a total of 1,152 public transport vehicles were taken from all three regions namely North, South, and Central Kerala. Sample vehicles are selected such a way as to represent the diverse types of operation and geographical areas. State-owned KSRTC is the major Public transport operator in Southern Kerala whereas private carriers serve predominantly in Northern Kerala. Public transportation in central Kerala is served both by private and KSRTC carriers. The questionnaire survey was conducted is major locations in Kerala. Thiruvananthapuram and Kottayam in Southern region, Ernakulam and Palakkad in Central and Malappuram, Kozhikode and Kannur in Northern region.

\section{Data Collection}

Data were collected with the help of a detailed questionnaire which was a revised model of the Manchester Driver Behavior Questionnaire. Public transport operators in each of the selected region were approached by our survey team and questions were dictated to them. Majority of operators cooperated with the survey and only a few showed reluctance to respond. The questions were based on their socio-economic, demographic and behavioral aspects. The collected data were organized such that analysis could be done for each region and also for all the regions combined.

\section{Analysis and Tools}

Primary analyses were done using Microsoft Excel spreadsheet where characteristics taken from the questionnaire data was arranged and required combination was taken. Even though each driver's response to different situations they face during driving is different, there are certain characteristics which can be said to be common to them. These common characteristics are the factors which have to be identified as the significant driving behavior. The driver behavior questionnaire used for the study contains a series of behavioral characteristics each of them being 
classified under violations, errors, and lapses. The main advantage of such a methodology is that the drivers are directly involved in the survey and errors can be reduced, provided they participate sincerely. The other methods which have been tried for traffic accident prediction, do not share these adantages.

The first part of the Questionnaire comprises of demographic details such as name, gender, age group, Sex, Place of Residence, Educational qualification, Marital Status, Driving Experience, Type of Vehicle Driven, No. of Trips per day, Per Day Trip Distance, Daily Riding hours and the No. of accidents. The second part is used to elicit data pertaining to driver behavior such as his violations, errors \& lapses. The Questionnaire altogether consisted of 51 questions which are relevant to driving behaviors. There are 17 questions in violation category, seven questions in the category of the error and eight questions in lapses category of Driving habits. Similarly, the questionnaire consists of another 19 questions which are relevant to non-driving behaviors out of which ten questions are relevant to errors and the rest corresponds to lapses. Violations were not defined under non-driving habits. The Software used for general analysis is Microsoft Excel.

From the data collected, it was identified that the age group of the participants ranged from 20 to 70 years. Most of the people were found to be educated up to school level i.e. $10^{\text {th }}$ grade, and a very few were found to be graduates. Most of the drivers were found to be married. The drivers were also asked to represent their experience in driving in a number of years. The number of trips per day and distance per day varied for each class of drivers. The number of trips varied from zero to ten and the total distance varied from zero to $500 \mathrm{Km}$. Then the drivers were also made to mark the number of accidents in which they were involved until now, which showed a variation from 0-4.

\section{Results and Discussion}

Based on the DBQ conducted for bus drivers from different parts of Kerala, a database of the behavioral aspects of the drivers was developed. From the collected data, we could understand how the basic driving behavior of the drivers' changes with respect to their varying sociodemographic backgrounds. And, these were the following results;

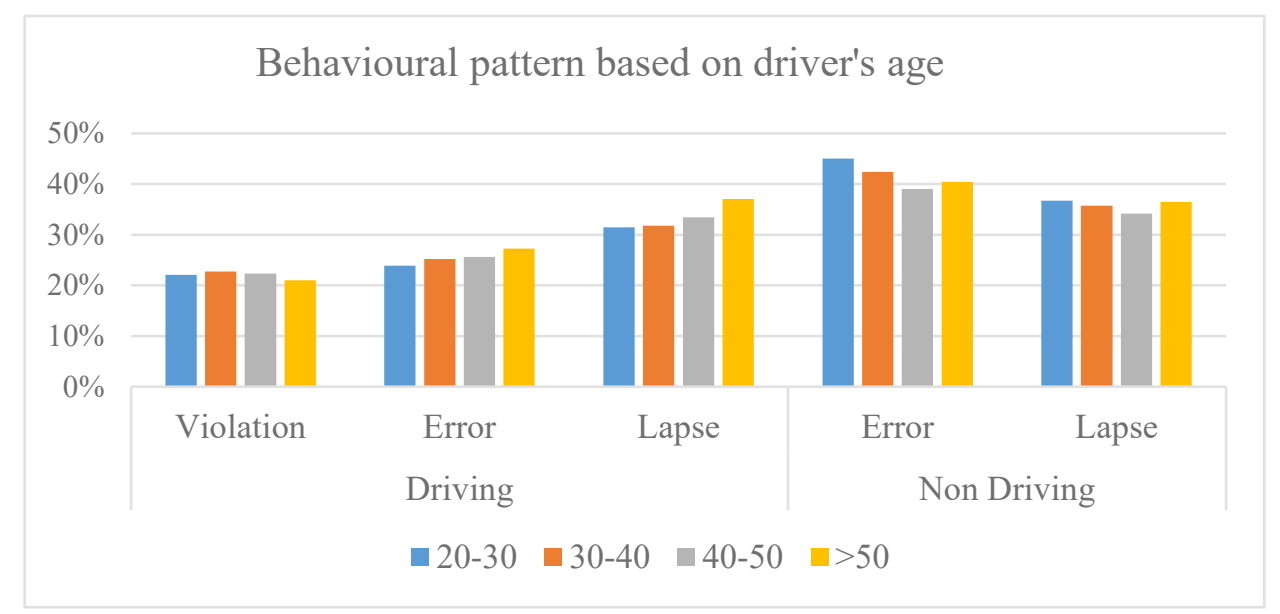

Figure 2. Behavioral pattern based on the driver's age 


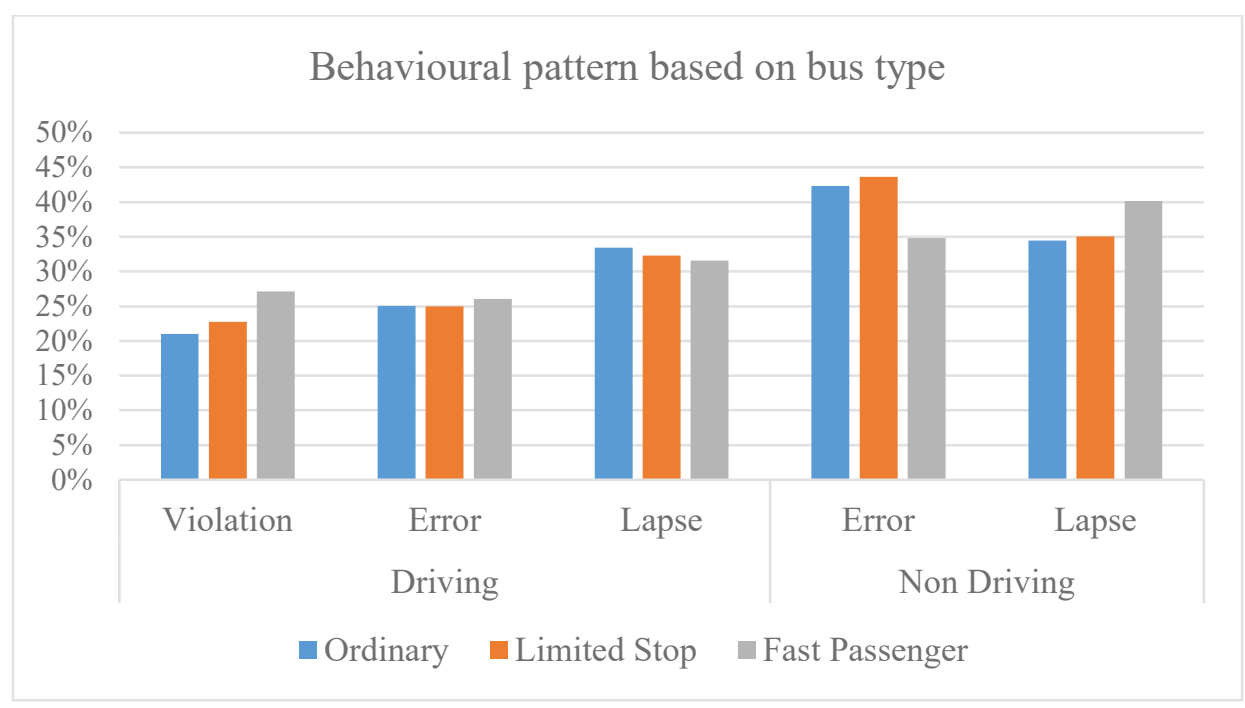

Figure 3. Behavioral pattern based on bus type

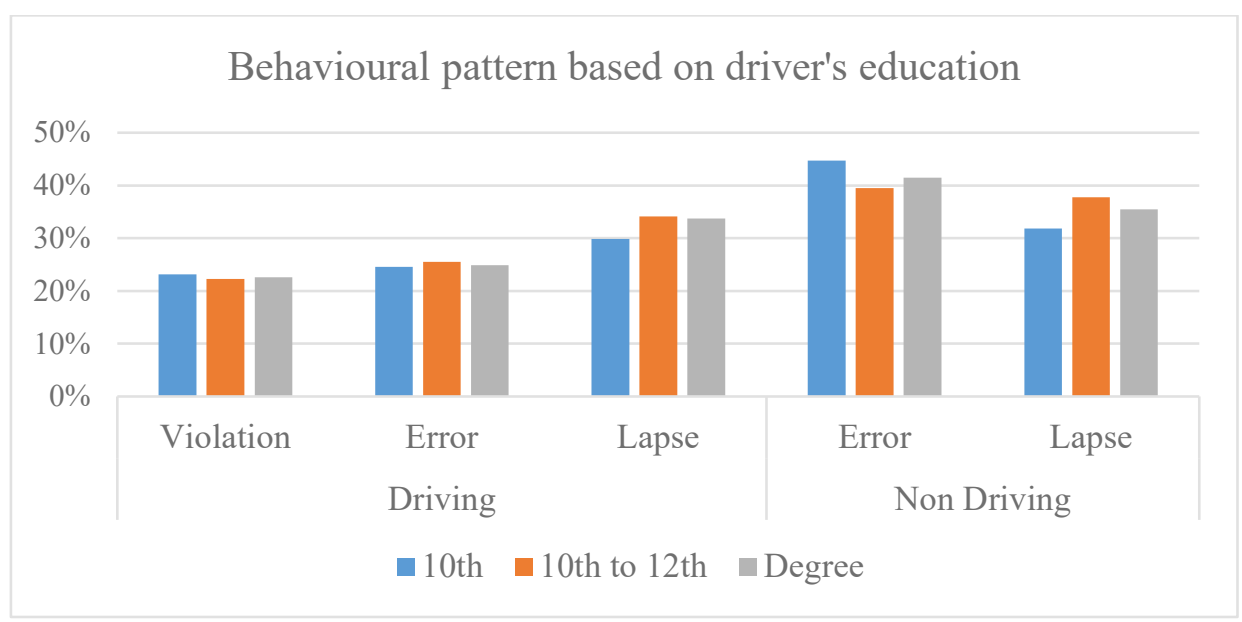

Figure 4. Behavioral pattern based on driver's education

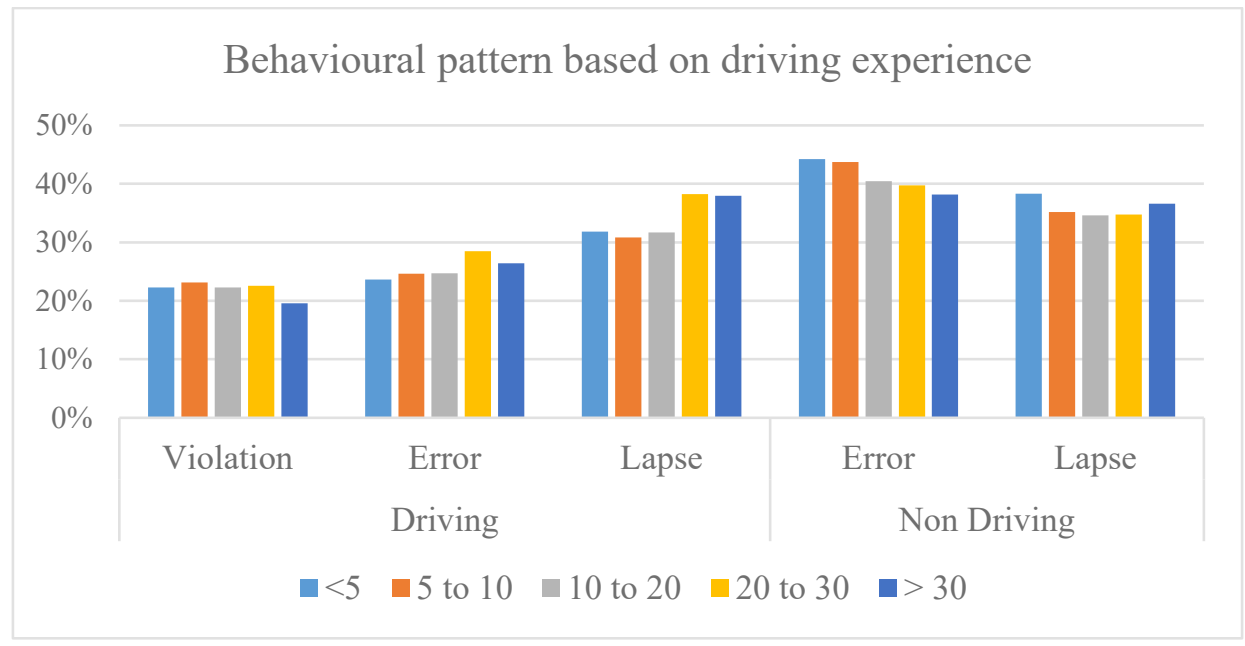

Figure 5. Behavioral pattern based on driving experience 


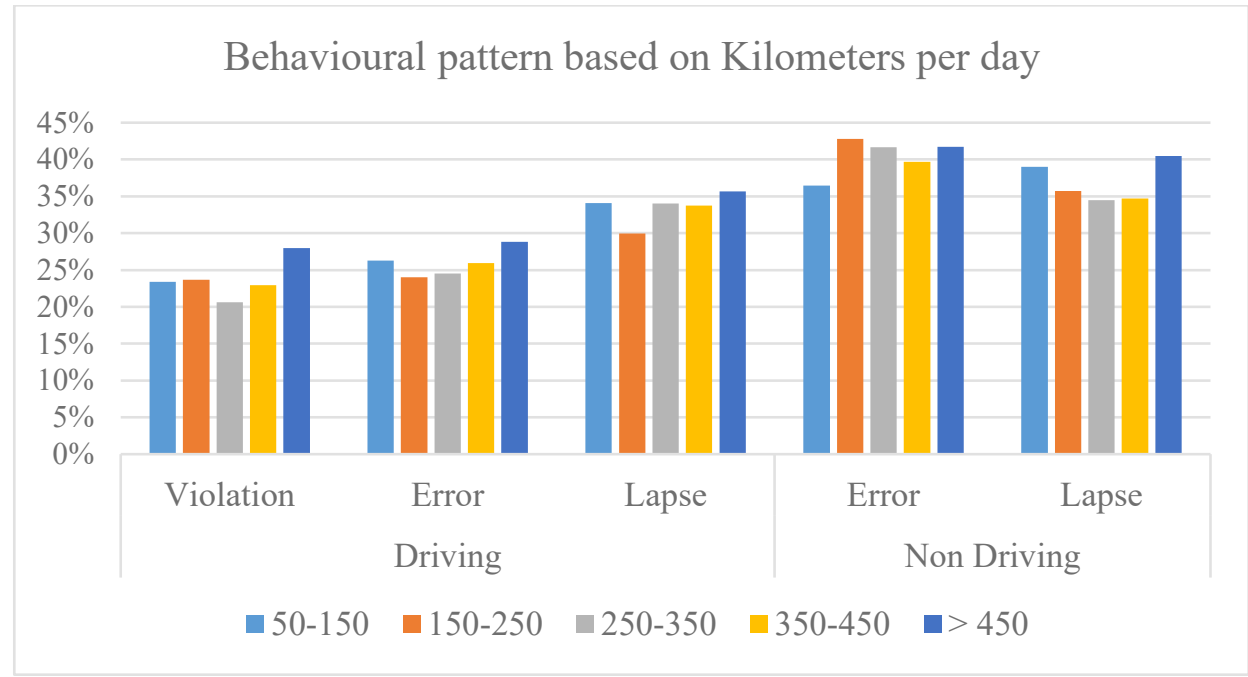

Figure 6. Behavioral Pattern based on kilometers driven per day

A multiple linear regression model was developed to state the relationship of independent variables with the occurrence of accidents. The model was developed with 1330 data samples of public transport drivers with the number of accidents taken as the dependent variable. The independent variables considered for the analysis were

1. Driving violations ( $\left.\mathrm{Dr}_{-} \mathrm{V}\right)$

2. Driving Errors (Dr_E)

3. Driving Lapses (Dr_L)

4. Non-driving Errors (Ndr_E)

5. Non-driving Lapses ( $\mathrm{Ndr}_{-} \mathrm{L}$ )

Summary of the model is given in Table 3 . The R-squared value was found to be 0.013 and the standard Error of estimate was 0.86 .

Table 3. Model summary

Model Summary

\begin{tabular}{|c|l|r|r|r|}
\hline Model & $\mathrm{R}$ & R Square & $\begin{array}{c}\text { Adjusted R } \\
\text { Square }\end{array}$ & $\begin{array}{c}\text { Std. Error of } \\
\text { the Estimate }\end{array}$ \\
\hline 1 & $.112^{\mathrm{a}}$ & .013 & .009 & .86682 \\
\hline
\end{tabular}

a. Predictors: (Constant), Ndr_L, Ndr_E, Dr_e, Dr_V, Dr_L

Table 4. Anova Table

ANOVA ${ }^{\mathrm{b}}$

\begin{tabular}{|ll|r|r|r|r|r|}
\hline Madel & & \multicolumn{1}{c|}{$\begin{array}{c}\text { Sum of } \\
\text { Squares }\end{array}$} & \multicolumn{1}{c|}{ df } & Mean Square & F & Sig. \\
\hline 1 & Regression & 12.617 & 5 & 2.523 & 3.358 & $.005^{a}$ \\
& Residual & 994.827 & 1324 & .751 & & \\
& Total & 1007.444 & 1329 & & & \\
\hline
\end{tabular}

a. Predictors: (Constant), Ndr_L, Ndr_E, Dr_e, Dr_v, Dr_L

b. Dependent Variable: Accidents 
Table 5. Table of coefficients

\begin{tabular}{|c|c|c|c|c|c|c|}
\hline \multicolumn{7}{|c|}{ Coefficients $^{\Xi}$} \\
\hline \multirow[b]{2}{*}{ Mad } & & \multicolumn{2}{|c|}{ Unstandardized Coefficients } & \multirow{2}{*}{$\begin{array}{c}\begin{array}{c}\text { Standardized } \\
\text { Coefficients }\end{array} \\
\text { Beta }\end{array}$} & \multirow[b]{2}{*}{$t$} & \multirow[b]{2}{*}{ Siq. } \\
\hline & & B & Std. Error & & & \\
\hline \multirow[t]{6}{*}{1} & (Constant) & .388 & .093 & & 4.173 & .000 \\
\hline & Dr_v & .053 & .020 & .079 & 2.631 & .009 \\
\hline & Dr_e & .000 & .019 & .001 & .016 & .987 \\
\hline & Dr_L & -.032 & .017 & -.059 & -1.910 & .056 \\
\hline & Ndr_E & -.017 & .016 & -.030 & -1.053 & .293 \\
\hline & Ndr_L & .030 & .016 & .052 & 1.855 & .064 \\
\hline
\end{tabular}

a. Dependent Variable: Accidents

From the model output it could be identified that all the independent variables except driving errors showed clear relationship with the number of accidents occurred to the driver during the driving period. The model equation is given as follows

$$
\text { No of Accidents }=0.388+0.053 D r_{V}-0.032 D r_{L}-0.017 N d r_{E}+0.03 N d r_{L}
$$

The model can be used to interpret the causative factors of accidents occurring among public transport drivers with respect to their driving and non-driving behaviour.

\section{Conclusions}

Based on the analyses, it could be observed that the driving behavior exhibited by drivers on road is developed through years of driving experience and is found to be affected by the socio-demographic background of the driver. Driver's age, Experience of the driver, kilometers are driven per day and hours have driven per day were found to have high influence in driving and non-driving behavior of the driver. Driving and non-driving habits of the drivers were classified into Violations, Errors, and Lapses.

It is noted that major cities like Thiruvananthapuram, Ernakulam, and Kozhikode showed higher violations. Driving lapses were found to be highest in Kottayam and Pathanamthitta districts. Nondriving errors were highest in Palakkad, Malappuram, and Kannur. It was observed that driving errors and lapses increased with age of drivers. While on the other hand, non-driving errors and lapses were higher for the age group ranging from 20-30. The highest driving violations were observed in Fast / Superfast buses compared to ordinary and limited stop buses. There was no significant effect for level of education of drivers in their behavioral pattern. Errors and lapses in married drivers showed slightly higher percentage compared to unmarried drivers whereas unmarried drivers were found to be higher in violations. Violations were found to be significantly lesser for drivers with an experience of more than 30 years. Violations, errors, and lapses were found to be the highest for drivers crossing 450 kilometers in a single day. Fewer violations were committed when the distance covered is less.

A linear regression model was run by taking the number of crashes as the dependent variable. The output of the model showed that a driving violations and non-driving lapsesshowed an important correlation with the occurrence of crashes in public transport drivers. The target group of the present study was public transport drivers native to the state of Kerala. The study is useful to identify the factors on the increasing proportion of crashes in which public transport buses in Kerala are involved. 


\section{References}

[1] Idris, F., Ismail, R. and Halim, F., W., (2015), The Model of Personality and Driver Behavior as Mediator on RoadAccident Involvement among Bus Driver in Riau Province Indonesia, International Journal of Psychology and Behavioral Sciences, 5(4), 148-153

[2] Wang, Y., Li, L., Feng, L., Peng, H., (2014) Professional drivers' views on risky driving behaviors and accidentliability: a questionnaire survey in Xining, Transportation Letters: The International Journal of TransportationResearch, Vol 6, 126-135.

[3] Bener, A., Ozkan, T., and Lajunen, T. (2008), The Driver Behavior Questionnaire in Arab Gulf countries: Qatar andThe United Arab Emirates, Accident analysis and prevention, 40 (2008), 1411-1417.

[4] Wishart, D., Freeman, J., \& Davey, J. (2006), Utilizing the Driver Behavior Questionnaire in an Organizational FleetSetting: Are Modifications Required, Journal of the Australasian College of Road Safety 17(2), 31-38.

[5] Musselwhite, C., (2006), Attitudes towards vehicle driving behavior: Categorizing and contextualizing risk, AccidentAnalysis and Prevention, Vol 38, 324-334

[6] Rohani M. M. andBuhari R., (2012)Bus Driver: Factors that influences Behaviour, A study by Smart Driving Research Centre, UniversitiTun Hussein Onn, Malaysia.

[7] Wang Y., Li L., Feng L. andPeng H. (2014) Professional drivers' views on risky driving behaviors and accident liability: a questionnaire survey in Xining, China, Transportation Letters, 6:3, 126-135. Winfred Arthur, Jr., and William G. Graziano, (1996), The FiveFactor Model, Conscientiousness, and Driving Accident Involvement, Journal of Personality, 64:3.

[8] Bifulco G. N., Galante F., Pariota L, Spena M. R., Del Gais P, (2014 ), Data Collection for Traffic and Drivers' Behaviour Studies: a large-scale survey, Procedia - Social and Behavioral Sciences 111, $721-730$.

[9] Lotan T., Toledo T., Prato C. G., (2009), Modeling the Behavior of novice young drivers using data from invehicle data recorders, Proceedings of the Fifth International Driving Symposium on Human Factors in Driver Assessment, Training and Vehicle Design.

[10] Ozkan T., Lajunen J., Summalaa H., (2006) Driver Behaviour Questionnaire: A follow-up study, Accident Analysis and Prevention 38, 386-395.

[11] Nanxiang L, Jain J. L. and BussoC.,(2012) Modeling of Driver Behavior in Real World Scenarios using Multiple Noninvasive Sensors, IEEE Transactions on Multimedia, Vol. X, No. X.

[12] Bifulco G. N., Galante, F, Pariota L., Russo Spena M. and Del Gais, P., Data Collection for Traffic and Drivers' Behaviour Studies: a large-scale survey, Procedia - Social and Behavioral Sciences 111 (2014) 721 - 730.

[13] Yilmaz V., Celic H. E., Risky driving attitudes and self-reported traffic violations among Turkish drivers: the Case of Eskisehir, DoğuşÜniversitesiDergisi, 7 (1) 2006, 127-138.

[14] Sarbescu P., Psychometric properties of the Manchester Driver Behaviour Questionnaire in Romania: Validation of a cross-cultural version, International Journal of Traffic and Transportation Psychology, Volume 1, Issue 1 (2013).

[15] de Winter, J., Dodou D., The Driver Behaviour Questionnaire as a predictor of accidents: A meta-analysis, Journal of Safety Research 41 (2010) 463-470.

[16] Ozkan T., Lajunen T., Chliaoutakis J. E., Parker D. andSummala H., Cross-cultural differences in driving behaviours: A comparison of six countries, Transportation Research: Part-F 9 (2006) 227-242. 